\title{
Neuroblastoma olfatorio. Todo lo que el radiólogo debe saber
}

\section{Olfactory Neuroblastoma. Everything the Radiologist Should Know}

\author{
Raquel Navas-Campo ${ }^{1}$ Leticia Moreno Caballero ${ }^{1}$ Ana Gasos Lafuente ${ }^{1}$ Pilar Tobajas Morlana ${ }^{1}$ \\ Eduardo Séez Valero ${ }^{1}$ María José Gimeno Peribáñez ${ }^{1}$
}

${ }^{1}$ Hospital Clínico Universitario Lozano Blesa, Zaragoza, España Rev Argent Radiol 2020;84:17-29.
Address for correspondence Raquel Navas Campo, Master, Avda. San Juan Bosco 15, Zaragoza, España (e-mail: raquelnavascampo@gmail.com).

\section{Resumen}

Palabras Clave

- Neuroblastoma olfatorio

- Estesioneuroblastoma

- cáncer de cabeza y cuello

- tomografía computarizada

- resonancia magnética
El neuroblastoma olfatorio (NBO) es un tumor maligno poco frecuente que se origina de las células neuroepiteliales olfativas. Su diagnóstico precoz es difícil debido a la poca especificidad de los síntomas que presentan los pacientes. Las pruebas de imagen juegan un papel importante en su diagnóstico y en la planificación quirúrgica, por lo que es importante que los radiólogos conozcan sus hallazgos y las diferentes clasificaciones que ayudarán a elegir el tratamiento más adecuado para cada tumor.

\author{
Abstract \\ Keywords \\ - Olfactory \\ neuroblastoma \\ - Esthesion- \\ euroblastoma \\ - Cancer of the Head \\ and Neck \\ - Computed \\ tomography \\ - Magnetic resonance \\ imaging
}

Olfactory neuroblastoma (ONB) is a rare malignant tumor that originates from olfactory neuroepithelial cells. Its early diagnosis is difficult due to the low specificity of the symptoms. Imaging tests play an important role in its diagnosis and surgical planning so it is important that radiologists know their findings and the different classifications that will help to choose the most appropriate treatment for each tumor.

\section{Introducción}

El neuroblastoma olfatorio (NBO) es un tumor maligno poco frecuente de la cavidad nasal superior, también llamado estesioneuroblastoma, estesioneuroepitelioma, estesioneurocitoma o tumor de la placoda olfatoria. ${ }^{1}$ Fue descrito por primera vez por Berger y colaboradores ${ }^{2}$ en 1924 , y el término más aceptado actualmente es "neuroblastoma olfatorio".,

El origen exacto de este tumor, así como la ubicación y tipo de célula, están en debate. ${ }^{5}$ Los sitios anatómicos de origen received

September 2, 2019

accepted

January 22, 2020
DOI https://doi.org/

10.1055/s-0040-1702993.

ISSN 1852-9992.
Copyright @ 2020, Sociedad Argentina de Radiología. Publicado por Thieme Revinter Publicações Ltda., Rio de Janeiro, Brazil. Todos los derechos reservados.

\section{License terms}

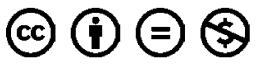


propuestos incluyen el órgano de Jacobson (órgano vomeronasal), el ganglio esfenopalatino, la placoda olfatoria ectodérmica, el ganglio de Loci, los ganglios simpáticos de la mucosa nasal y la mucosa nasal en sí. Sin embargo, el origen más probable del NBO es en las células neurales basales de la mucosa olfatoria. ${ }^{5-7}$ Eso está respaldado por el hecho de que los filamentos neurales están presentes en las células tumorales, como demostró Trojanowaski y colaboradores ${ }^{8}$ en 1982, y por el análisis molecular, como demostró Carney y colaboradores ${ }^{9}$ en 1995, al expresar el gen Drosophila acaetscute (hASH1), involucrado en el desarrollo neuronal olfativo inmaduro. ${ }^{5,6,10}$

Este tumor constituye aproximadamente entre el 2\%$3 \%$ de todas las neoplasias intranasales. ${ }^{11}$ Afecta por igual a ambos sexos. Puede presentarse en todas las edades y, aunque se creía que esos tumores presentaban una distribución de edad bimodal con un pico en la segunda y otro en la sexta década de vida, algunos estudios recientes apoyan una distribución uniforme en todas las edades, con pico en la quinta y la sexta décadas. 3,4,6,12,13

La inespecificidad de los síntomas y la agresividad local del tumor, favorecen el desarrollo de enfermedad localmente avanzada con diseminación por vía submucosa a los senos paranasales y a la fosa craneal anterior, a través de la placa cribiforme en un gran número de pacientes. ${ }^{14-16}$ La enfermedad metastásica afecta entre el 17 y el $48 \%$ de los pacientes. ${ }^{17}$ Los ganglios linfáticos cervicales son los sitios más frecuentes de metástasis, con una incidencia que varía entre el 20 y el 30\%, seguidos de pulmón, hueso y, rara vez, de hígado, mediastino, glándula suprarrenal, ovario, bazo o parótida o incluso mama. ${ }^{12,18-24}$

Las pruebas de imagen juegan un papel importante en su diagnóstico y en la planificación quirúrgica, por lo que es imprescindible que los radiólogos conozcan sus hallazgos en las diferentes pruebas de imagen y las clasificaciones que ayudarán a elegir el tratamiento más adecuado para cada tumor.

\section{Histología e inmunohistoquímica}

Histológicamente, el NBO está formado por células pequeñas, redondas, de color azul, un poco más grandes que los linfocitos maduros. Esas células tienen núcleos con forma de redonda a ovalada, con escaso citoplasma y cromatina bien definida. Además, presentan capas de células malignas organizadas en lóbulos a través de septos fibrosos vasculares delgados, rosetas neurales verdaderas (tipo Flexner - Wintersteiner) y pseudorosetas (Tipo Homer Wright). ${ }^{23}$

El diagnóstico diferencial del NBO incluye todas las neoplasias de células azules pequeñas que surgen en el tracto sinonasal. Ellas incluyen neoplasias epiteliales como el carcinoma sinonasal indiferenciado, el carcinoma neuroendocrino sinonasal, el carcinoma escamoso y el melanoma; neoplasias no epiteliales como el rabdomiosarcoma, tumores linfoproliferativos y lesiones benignas como el papiloma invertido y el schwanoma. ${ }^{25}$

El diagnóstico diferencial es posible, especialmente en los casos de alto grado, solo por técnicas de inmunohistoquímica. $^{26}$ Las células tumorales del NBO expresan marcadores neuronales como la sinaptofisina, la cromogranina o la enolasa específica de la neurona, así como la calretinina, que los diferencian de otros tipos de tumores de células azules redondas pequeñas. ${ }^{27,28}$

Las células de la periferia de los lóbulos son muy reactivas para la proteína S100. Las citoqueratinas suelen ser negativas, aunque en algunos casos aislados se puede observar una expresión irregular. ${ }^{29}$

\section{Clasificación histológica}

El sistema de clasificación histológica de Hyams y colaboradores $^{30}$ ( - Tabla 1) se desarrolló en 1988, como una herramienta importante para determinar el pronóstico, tanto de recurrencia como de supervivencia. ${ }^{30,31}$ Los criterios subyacentes a esa clasificación son la actividad mitótica, la conservación de la arquitectura nativa, las características de la matriz, el polimorfismo nuclear, la existencia de rosetas y la necrosis tumoral. ${ }^{32}$ Ese sistema de clasificación estratifica los tumores en cuatro grupos que van desde bien diferenciado (grado I) hasta el menos diferenciado (grado IV). Es un sistema subjetivo complejo y, a veces, la separación definitiva entre los grados es difícil. Por ello, ha habido una tendencia a agrupar esas categorías en bajo grado, que abarca los grados I y II, y alto grado, que implica los grados III y IV, para proporcionar una descripción más fácil de esos tumores en correlación con el pronóstico. ${ }^{33}$ Existe una creciente evidencia en la literatura de que esa clasificación puede usarse como un indicador de pronóstico. Se encontró que los tumores de alto grado en la clasificación de Hyams están asociados con una enfermedad locorregional más agresiva y un peor resultado de supervivencia en comparación con los tumores de bajo grado. ${ }^{4,34,35}$ Además, la clasificación de Hyams puede añadir un valor para guiar la selección del tratamiento adyuvante. ${ }^{34}$

Tabla 1 Clasificación histológica de Hyams. * Rosetas HW: Rosetas verdaderas tipo Flexner - Wintersteiner. * Pseudorosetas FW: Pseudorosetas tipo Homer Wright

\begin{tabular}{|l|l|l|l|l|l|l|}
\hline GRADO & $\begin{array}{l}\text { Preservación de la } \\
\text { arquitectura lobular }\end{array}$ & $\begin{array}{l}\text { Índice } \\
\text { mitótico }\end{array}$ & $\begin{array}{l}\text { Polimorfismo } \\
\text { nuclear }\end{array}$ & $\begin{array}{l}\text { Matriz } \\
\text { fibrilar }\end{array}$ & Rosetas & Necrosis \\
\hline I & + & Ninguno & Ninguno & Prominente & Rosetas HW & No \\
\hline II & + & Bajo & Moderado & Presente & Rosetas HW & No \\
\hline III & + I- & Moderado & Prominente & Presente & Pseudorosetas FW & Raro \\
\hline IV & + I- & Alto & Marcado & Ausente & Ninguna & Frecuente \\
\hline
\end{tabular}




\section{Clínica}

Los síntomas más comunes de presentación son la obstrucción nasal seguida de la epistaxis recurrente. Otros síntomas incluyen dolor de cabeza, dolor facial, hiposmia y rinorrea. $^{36-45}$ Ocasionalmente, se presenta como una masa nasal asintomática que se descubre accidentalmente. ${ }^{45}$ La enfermedad más avanzada se presenta con síntomas de extensión local más allá de la nariz y senos paranasales, como epífora, diplopía, proptosis y disminución de la agudeza visual. ${ }^{36,43-45}$ De manera poco frecuente, se pueden encontrar síntomas de afectación intracraneal, como síntomas del lóbulo frontal y convulsiones. ${ }^{38,45}$ En raras ocasiones, se han notificado síntomas paraneoplásicos debidos a la secreción de hormona ectópica, incluidos el síndrome de Cushing y la hiponatremia secundaria a la secreción de hormona adrenocorticotrópica (ACTH) y antidiurética (ADH) respectivamente. ${ }^{45-48}$ Localmente, la enfermedad avanzada puede presentar signos de invasión y destrucción de las estructuras vecinas, como la órbita, el cerebro, los tejidos blandos faciales y la piel. ${ }^{3,6,38}$

Debido a la no especificidad de los síntomas tempranos, el diagnóstico generalmente se retrasa, con un tiempo promedio de 6 a 12 meses entre el inicio de los síntomas y el diagnóstico. ${ }^{3,6,19,38,49}$

\section{Diagnóstico por imagen}

Las imágenes son muy importantes en el diagnóstico y la estadificación del NBO. Generalmente se requiere una combinación de tomografía computarizada (TC) y resonancia magnética (RM) para evaluar de manera óptima la extensión del tumor. ${ }^{38,49}$ Ambas pruebas permiten diagnosticar, definir la extensión del tumor, la estadificación y el abordaje quirúrgico, monitorizar y evaluar la respuesta al tratamiento.

La TC de corte fino (espesor de corte de $1 \mathrm{~mm}$ ) con reconstrucciones en plano coronal y sagital, es la mejor prueba de imagen inicial para el estudio del NBO. En la TC, aparece como una masa homogénea de tejido blando en la bóveda nasal con realce moderado y uniforme (-Figs. 1 y 2 ). Se pueden encontrar calcificaciones punteadas dispersas ( - Figs. 2-4, 5a, 6). ${ }^{50}$ El valor principal de la TC es una mejor definición de la afectación ósea en comparación con la RM. La TC ayuda a evaluar la erosión ósea de la placa cribiforme, la fóvea etmoidal y la lámina papirácea (-Figs. 1-4, 5a, 8). Sin embargo, la remodelación ósea sin erosión puede presentarse en algunos casos debido a su patrón de crecimiento indolente. ${ }^{3,35,49}$ Los estudios de TC generalmente revelan un patrón lítico y muy raramente hiperostosis dominante que simula displasia fibrosa. ${ }^{51}$ La TC también es útil para evaluar la presencia de metástasis regionales en cuello y a distancia. ${ }^{52,53}$

La RM es la prueba de imagen de elección para evaluar los detalles de la extensión y la estadificación locorregional del tumor. La RM es superior a la TC para determinar el grado de afectación del tejido blando (-Fig. 9) con una mejor evaluación de la afectación intracraneal (-Figs. 10-14), orbital (-Figs. 14 y 15), de la base del cráneo y la invasión perineural. ${ }^{53,54}$ La RM tiene un valor añadido para distinguir la afectación dural de la del parénquima cerebral (-Fig. 12). ${ }^{55}$ En la RM, el NBO aparece hipointenso respecto a la sustancia gris en imágenes ponderadas en T1 $\mathrm{y}$ de isointenso a hiperintenso en las imágenes ponderadas en T2 (-Figs. 10-15). ${ }^{56}$ Muestra un realce homogéneo, excepto en áreas con hemorragia o necrosis. Además, permite diferenciar las secreciones retenidas del tumor, al ser estas hiperintensas ponderadas en T2. ${ }^{53,55}$ Los hallazgos de imágenes clásicos incluyen una masa "en forma de

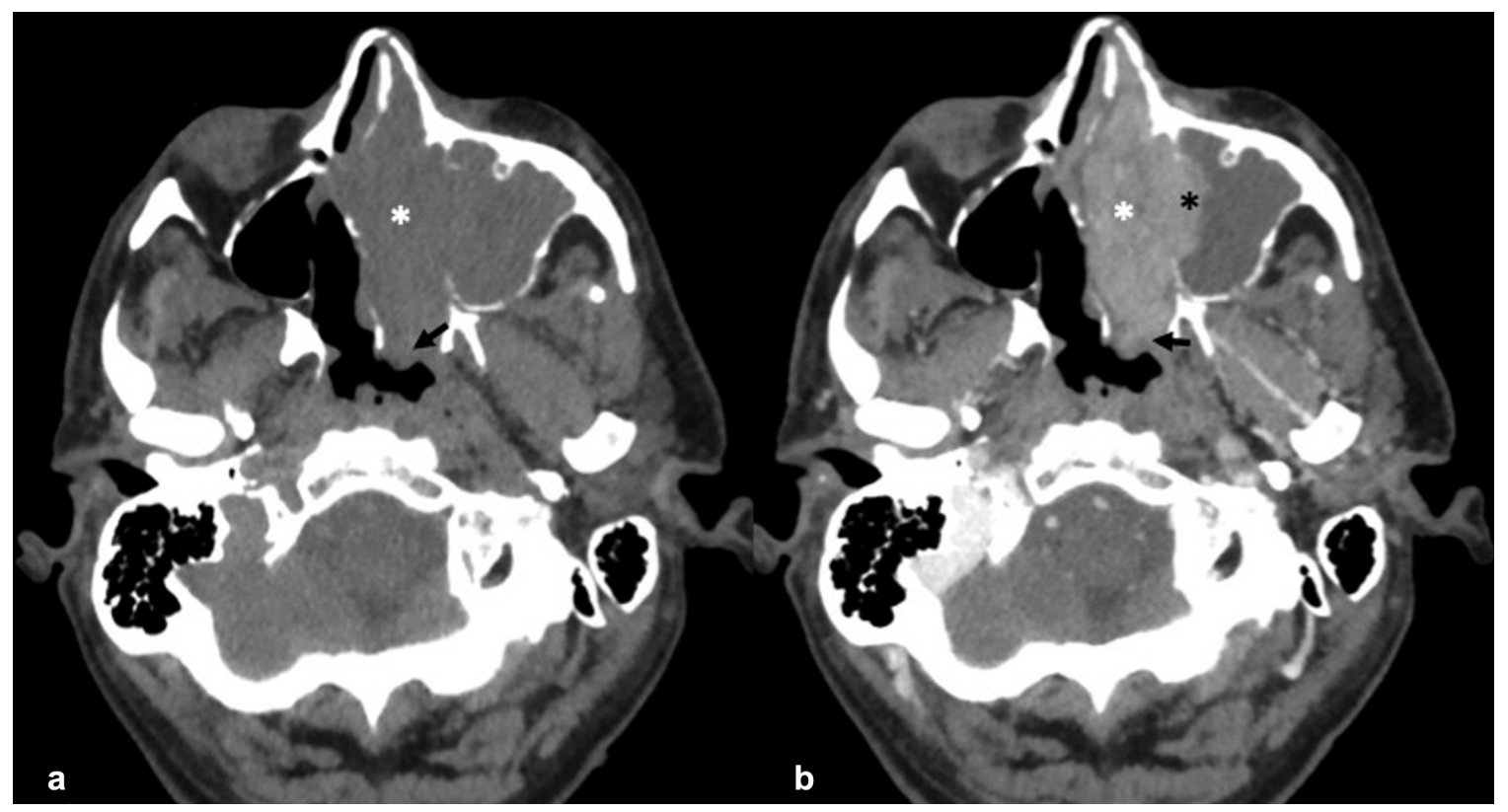

Fig. 1 (a) TC craneoencefálica sin contraste intravenoso en plano axial. Lesión de tejido blando ocupante de espacio homogénea que ocupa fosa nasal izquierda (asterisco blanco) y presenta extensión coanal izquierda (flecha negra) y destrucción ósea con extensión a seno maxilar izquierdo (asterisco negro). (b) TC craneoencefálica con contraste intravenoso yodado en plano axial. Tras la administración de contraste, la lesión presenta un realce moderado. 


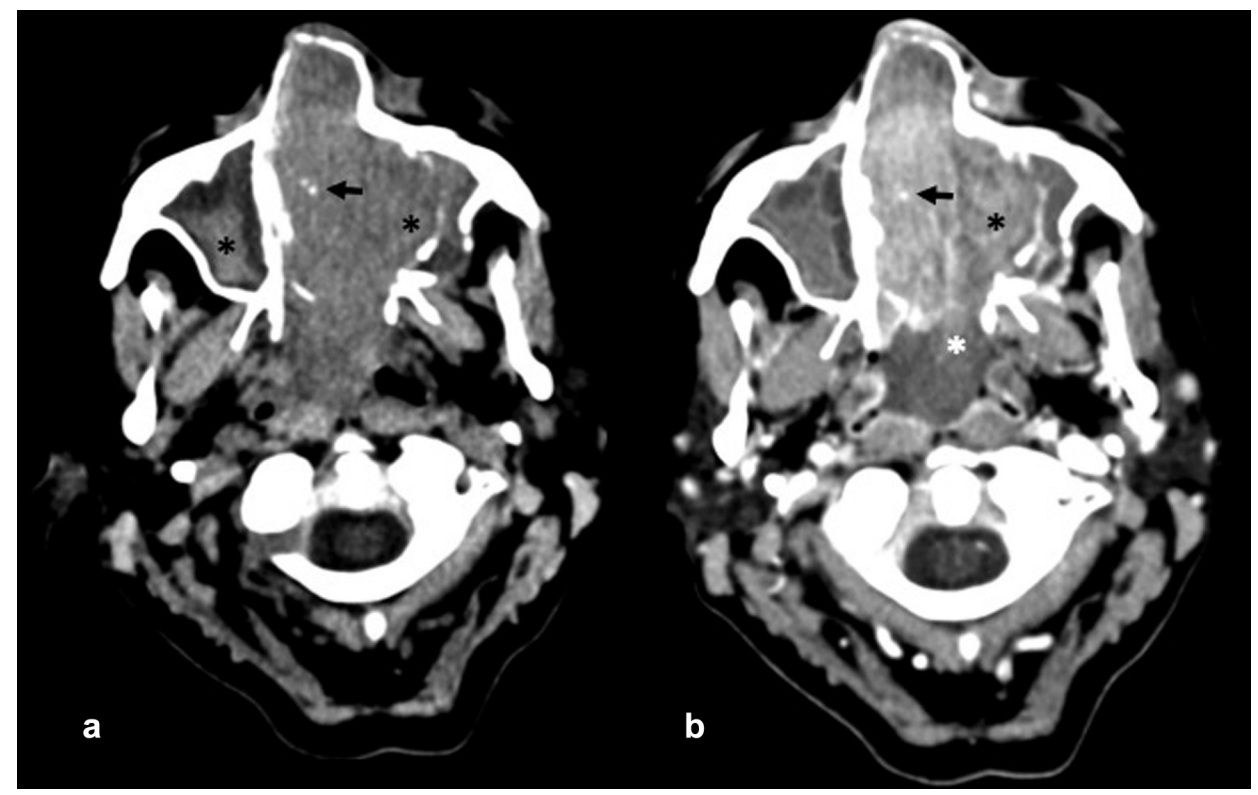

Fig. 2 TC craneoencefálica plano axial (a) sin contraste intravenoso y (b) con contraste intravenoso yodado. Masa homogénea de tejido blando con pequeñas calcificaciones puntiformes en su interior (flechas negras), que ocupa fosas nasales con destrucción ósea y extensión a ambos senos maxilares (asteriscos negros), así como extensión caudal posterior a nasofaringe (asterisco blanco).

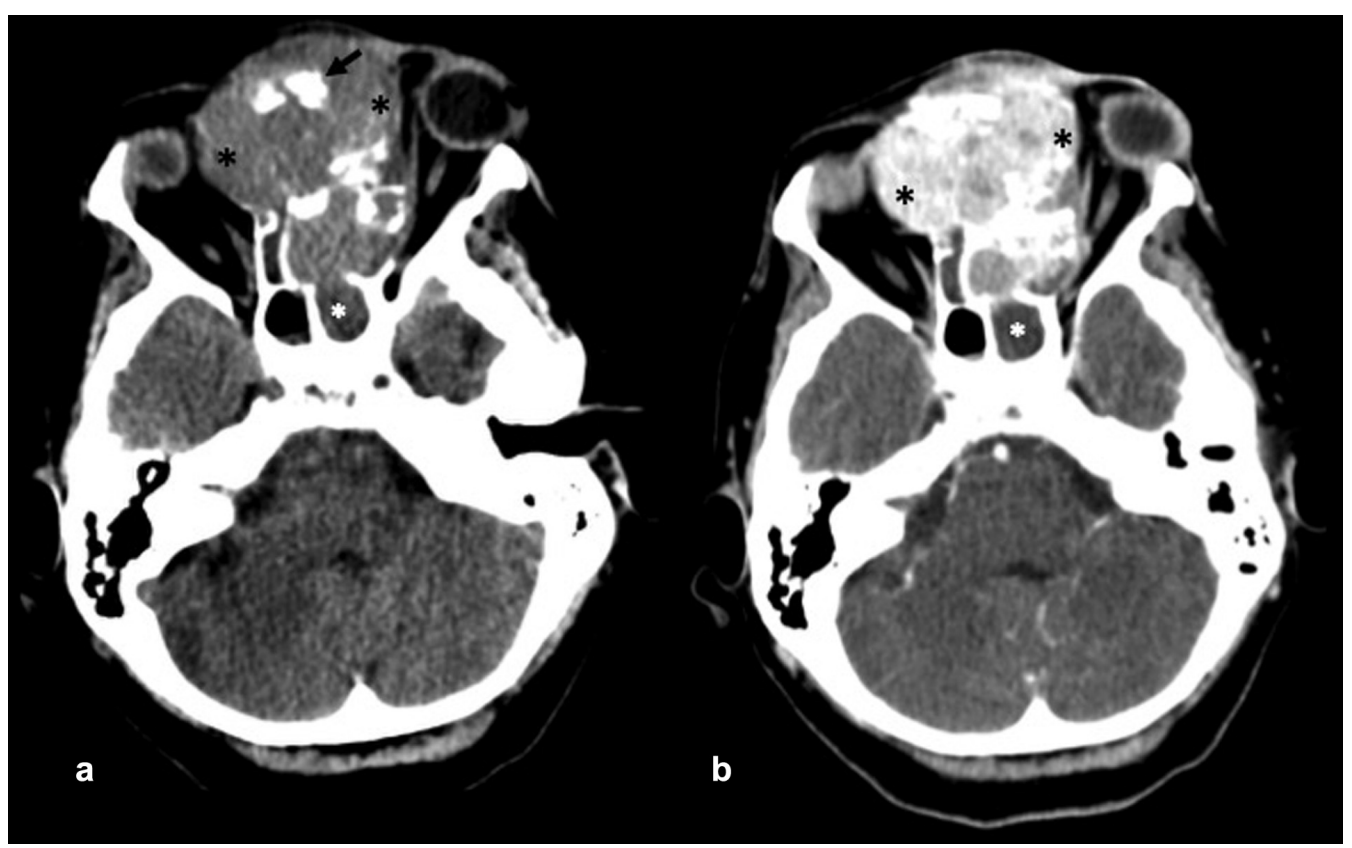

Fig. 3 (a) TC craneoencefálica plano axial sin contraste intravenoso. Voluminosa tumoración de tejido blando que ocupa fosas nasales y afecta a ambas órbitas (asteriscos negros), predominantemente la derecha y al seno esfenoidal (asteriscos blancos). Presenta calcificaciones en su interior (flecha negra). (b) TC craneoencefálica plano axial con contraste intravenoso yodado. Tras la administración de contraste intravenoso, la tumoración descrita presenta realce moderadamente homogéneo.

mancuerna" que se extiende a través de la placa cribiforme (-Fig. 12), con la parte estrecha a nivel de la placa. Los quistes tumorales periféricos (-Figs. 5b, 12, 14, 16) y las calcificaciones moteadas son bastante característicos de NBO. ${ }^{1}$

Las secuencias de RM con saturación de la grasa ayudan a diferenciar el tumor de la grasa orbital y los músculos. Un margen suave de la interfaz tumor-grasa sugiere que la lesión está contenida en la fascia periorbital (-Fig. 15), mientras que un margen irregular favorece la invasión franca de la órbita. ${ }^{35,49,57}$ Sin embargo, el diagnóstico definitivo de invasión de la duramadre y los tejidos periorbitarios solo es posible en la cirugía. ${ }^{49}$

La obtención de imágenes del cuello en pacientes con NBO es crucial porque las metástasis en ganglios linfáticos del cuello, se presentan en el $5 \%$ de los pacientes. ${ }^{33}$ Además, se ha estimado que más del $23 \%$ de los pacientes pueden desarrollar metástasis en los ganglios linfáticos cervicales. $^{20}$ Howell y colaboradores ${ }^{52}$ describieron un patrón predecible de metástasis a los ganglios linfáticos 


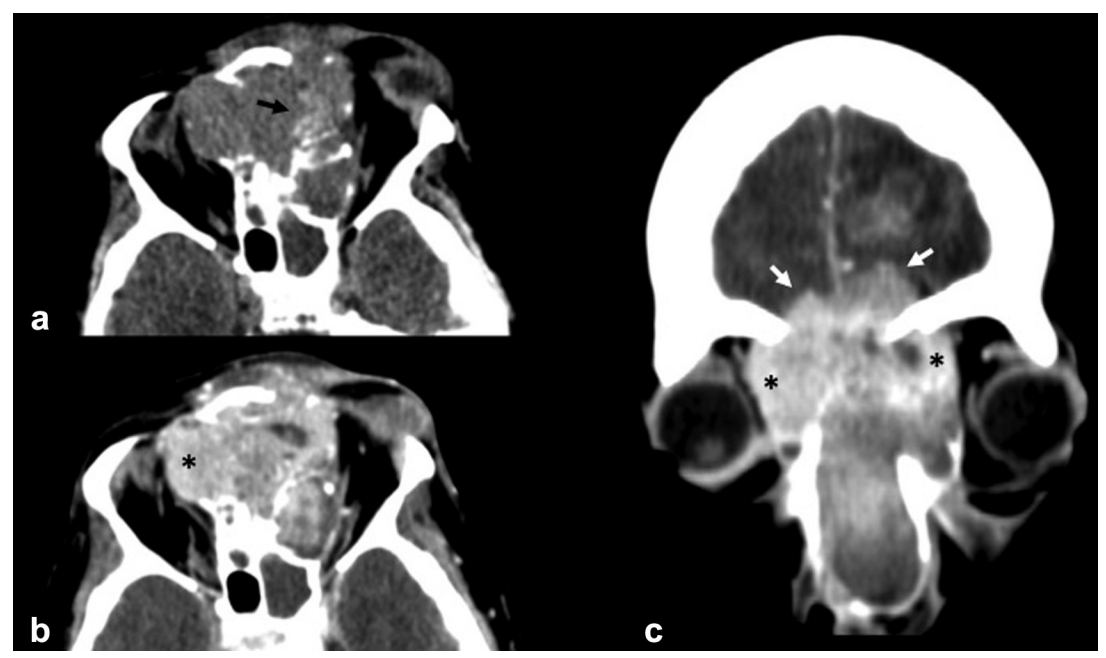

Fig. 4 TC craneoencefálica plano axial (a) sin contraste intravenoso y (b) con contraste intravenoso yodado. (c) Reconstrucción Multiplanar (MPR) coronal de TC craneoencefálica con contraste intravenoso yodado. Lesión de fosas nasales con calcificaciones punteadas en su interior (flechas negras), que capta contraste y que produce destrucción ósea con invasión de ambas órbitas (asteriscos negros) y seno frontal con extensión intracraneal frontal (flechas blancas).

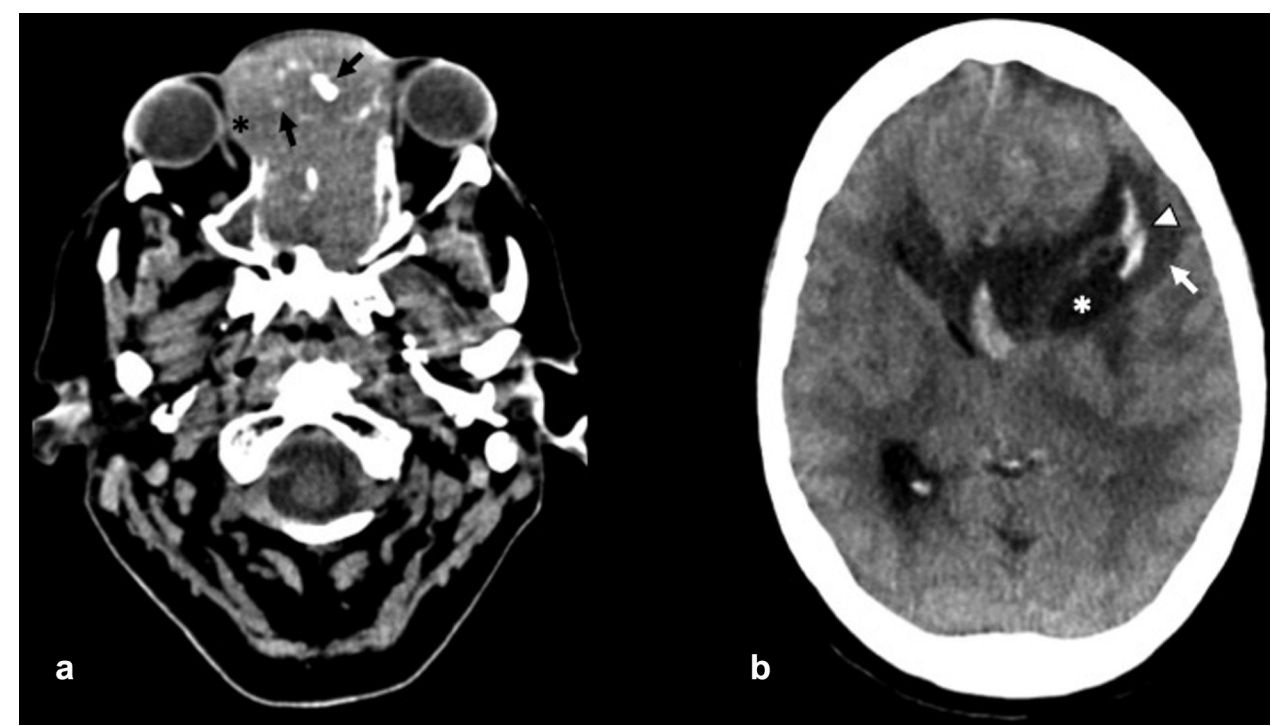

Fig. 5 TC craneoencefálica plano axial sin contraste intravenoso. (a) Voluminosa masa de partes blandas con calcificaciones puntiformes en su interior (flechas negras) que ocupa fosas nasales y produce destrucción ósea extendiéndose a orbita derecha y seno frontal (asterisco negro). (b) La masa también se extiende a fosa cerebral anterior, donde presenta contenido quístico en su polo posterior (asterisco blanco) y edema perilesional (flecha blanca). Ejerce un importante efecto de masa con compresión del asta frontal de ventrículo lateral izquierdo y desplazamiento de la línea media hacia la derecha. Además, se observan varios focos de sangrado parenquimatoso asociados (punta de flecha blanca).

cervicales, que típicamente involucra a los ganglios del nivel II (93\%), con una afectación frecuente del nivel I (57\%), nivel III (50\%) y los ganglios retrofaríngeos (43\%).

Una de las localizaciones más frecuentes de metástasis a distancia es el hueso, siendo la columna vertebral la ubicación más común $(86 \%){ }^{58}$ Se han descrito casos de metástasis óseas asintomáticas $\mathrm{y}$, por lo tanto, se debe incluir una gammagrafía ósea en el diagnóstico. ${ }^{33}$

La evaluación del tumor recurrente debe incluir tanto TC como RM. Las características de imagen del tumor recurrente no difieren de su apariencia en la presentación inicial. Se ha sugerido el siguiente protocolo de seguimiento para detectar precozmente las recurrencias: RM con contraste 2-4 meses después de completar todo el tratamiento. Posteriormente, se repite cada 4-6 meses durante 5 años, y pasado ese tiempo, se realiza anualmente durante la vida del paciente. ${ }^{59}$ El protocolo de RM utilizado en nuestro servicio consiste en la realización de secuencias ponderadas en T1, T2 y T1 con supresión grasa sin y con contraste para el estudio a nivel nasosinusal y secuencias ponderadas en T1, T2, FLAIR, DWEPI y T1 con contraste para el estudio encefálico. Además, se debe hacer una radiografía de tórax anual para excluir la presencia de metástasis. ${ }^{59}$

\section{Clasificación/Estadificación por imagen}

Se han propuesto varios sistemas de estadificación para el NBO, pero ningún sistema único es aceptado universalmente. 


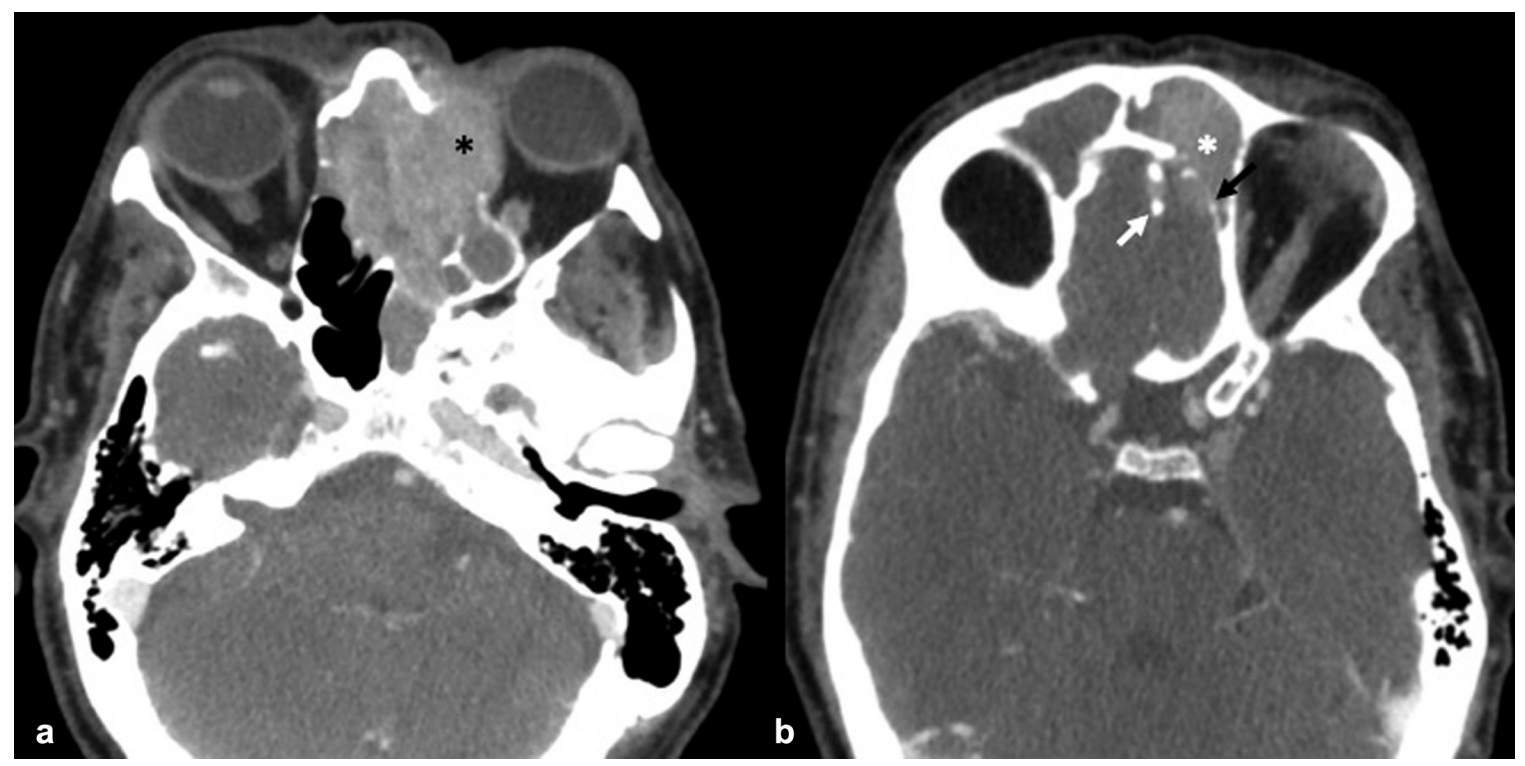

Fig. 6 (a) TC craneoencefálica con contraste intravenoso yodado en plano axial. Muestra masa de partes blandas con pequeñas calcificaciones puntiformes en su interior (flecha blanca), que da lugar a una destrucción ósea con extensión intraorbitaria izquierda extraconal que comprime el músculo recto interno izquierdo (asterisco negro), así como extensión a celdillas etmoidales anteriores bilaterales. (b) TC craneoencefálica con contraste intravenoso yodado en plano axial. Extensión de la lesión de partes blandas a seno frontal izquierdo (asterisco blanco) con destrucción ósea (flecha negra) y extensión intracraneal en fosa anterior.

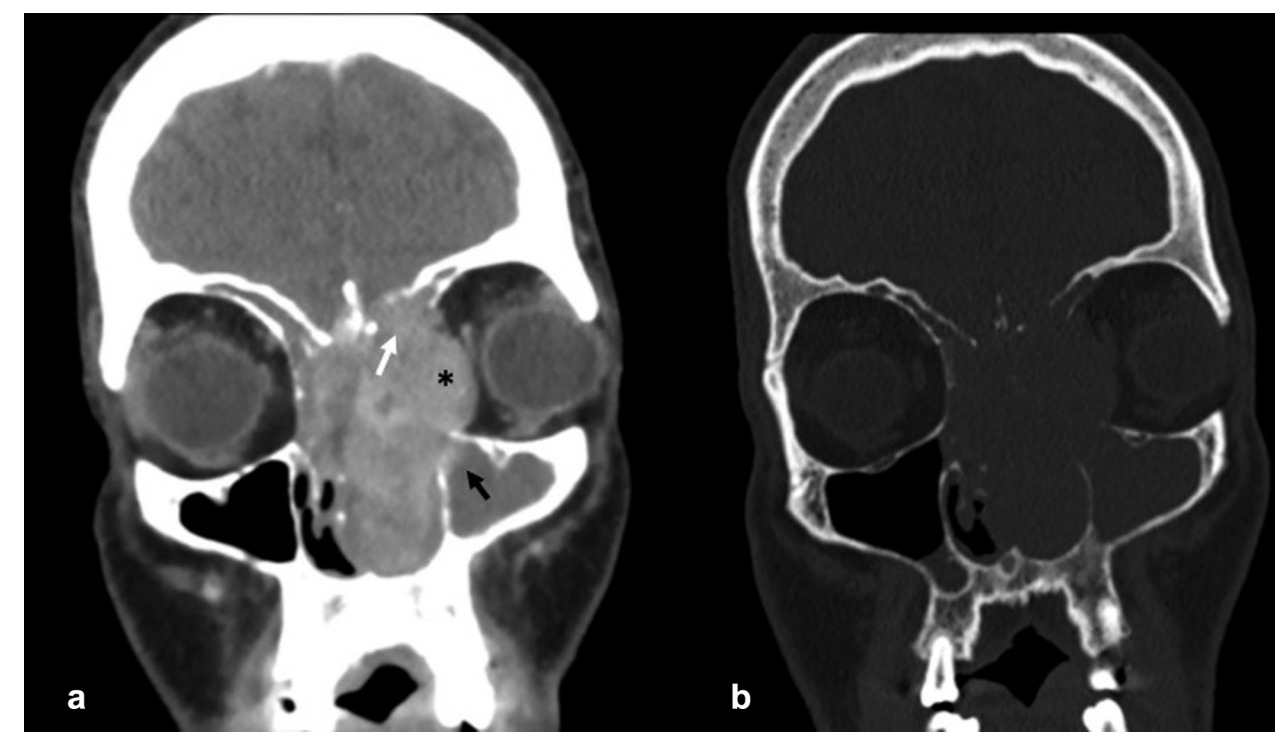

Fig. 7 (a) MPR plano coronal de TC craneoencefálica con contraste intravenoso yodado. Gran masa de partes blandas que ocupa la fosa nasal izquierda con destrucción ósea y extensión intraorbitaria izquierda (asterisco negro), extensión a seno maxilar izquierdo (flecha negra), destrucción del suelo del seno frontal izquierdo y destrucción de la lámina cribiforme izquierda y extensión intracraneal (flecha blanca). (b) MPR plano coronal de TC craneoencefálica con ventana de hueso. Se objetiva destrucción de lámina papirácea, celdillas etmoidales, hueso lacrimal izquierdo, lámina orbitaria izquierda, la lámina cribiforme izquierda y apófisis crita galli.

El primero en proponer una clasificación fue Kadish. En esa clasificación, se dividían los tumores en tres categorías según su extensión: Grupo A, el tumor está limitado a la cavidad nasal; Grupo B, se extiende a senos paranasales; Grupo C, se extiende más allá de senos paranasales. ${ }^{18}$

Esa clasificación fue modificada en 1993 por Morita y colaboradores, ${ }^{60}$ quienes añadieron la etapa $\mathrm{D}$ para la diseminación a los ganglios linfáticos de la región cervical y las metástasis a distancia (- Tabla 2). ${ }^{19,61}$ Algunos estudios han descrito que la clasificación de Kadish modificada puede ser un predictor útil en la supervivencia. ${ }^{12,49}$ El estudio de
Jethanamest y colaboradores $^{12}$ encontró que en esa clasificación, la afectación de los ganglios linfáticos y la edad en el momento del diagnóstico, eran factores pronósticos. Sin embargo, la rareza de la enfermedad dificulta la validación de los sistemas de estadificación, y el valor pronóstico de esa clasificación no ha sido confirmado en otros estudios como el de Konuthula y coraboradores. ${ }^{62}$

En 1990, Biller y colaboradores ${ }^{61}$ proponen otra clasificación ( - Tabla 3 ), en la que T1 indica que el tumor afecta a la cavidad nasal y senos paranasales, excluyendo el esfenoides, con o sin erosión del hueso de la fosa craneal 


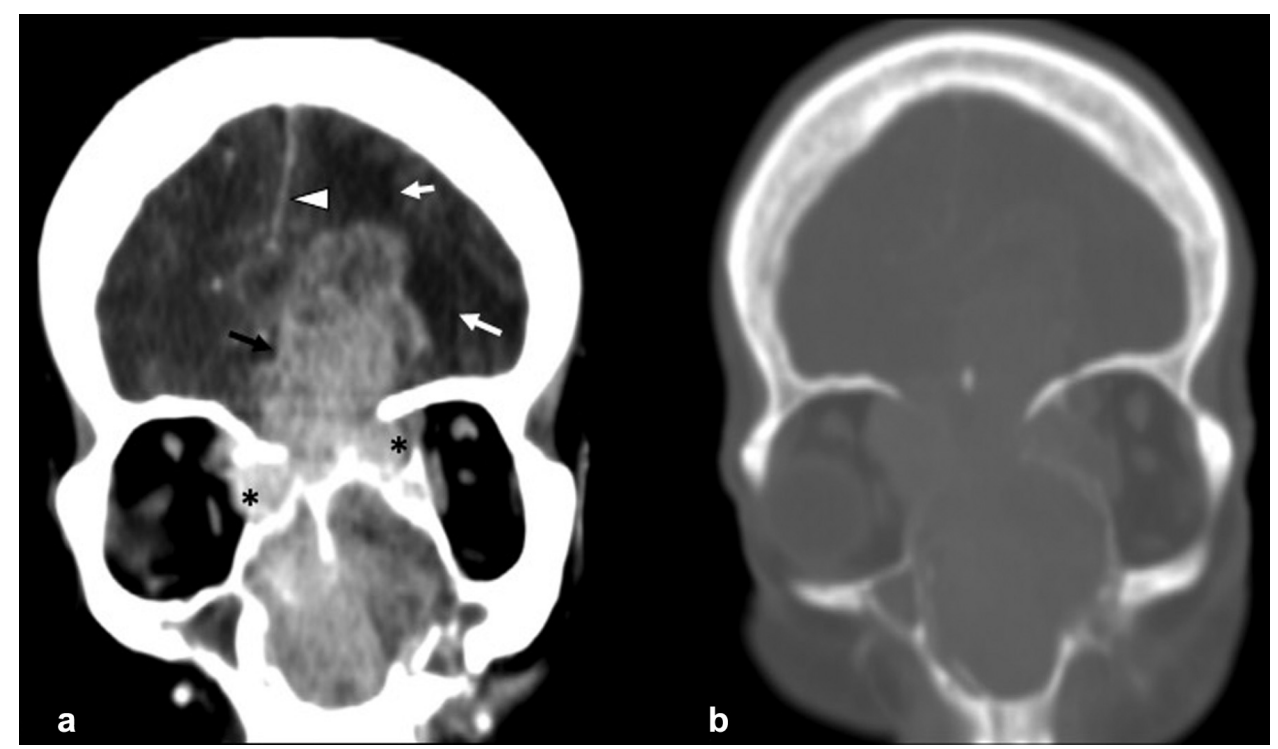

Fig. 8 MPR coronal de TC craneoencefálica con contraste intravenoso yodado (a) ventana de partes blandas y (b) ventana de hueso. Voluminosa tumoración que ocupa fosas nasales con extensión a ambas órbitas, predominantemente órbita derecha (asterisco negro) y seno frontal. Destrucción ósea de lámina papirácea, lámina orbitaria y la lámina cribosa. Extensión intracraneal parenquimatosa con afectación frontal izquierda extensa (flecha negra) y edema asociado (flecha blanca), que ejerce efecto de masa con herniación subfalcial y desviación de línea media a la derecha (punta de flecha blanca).

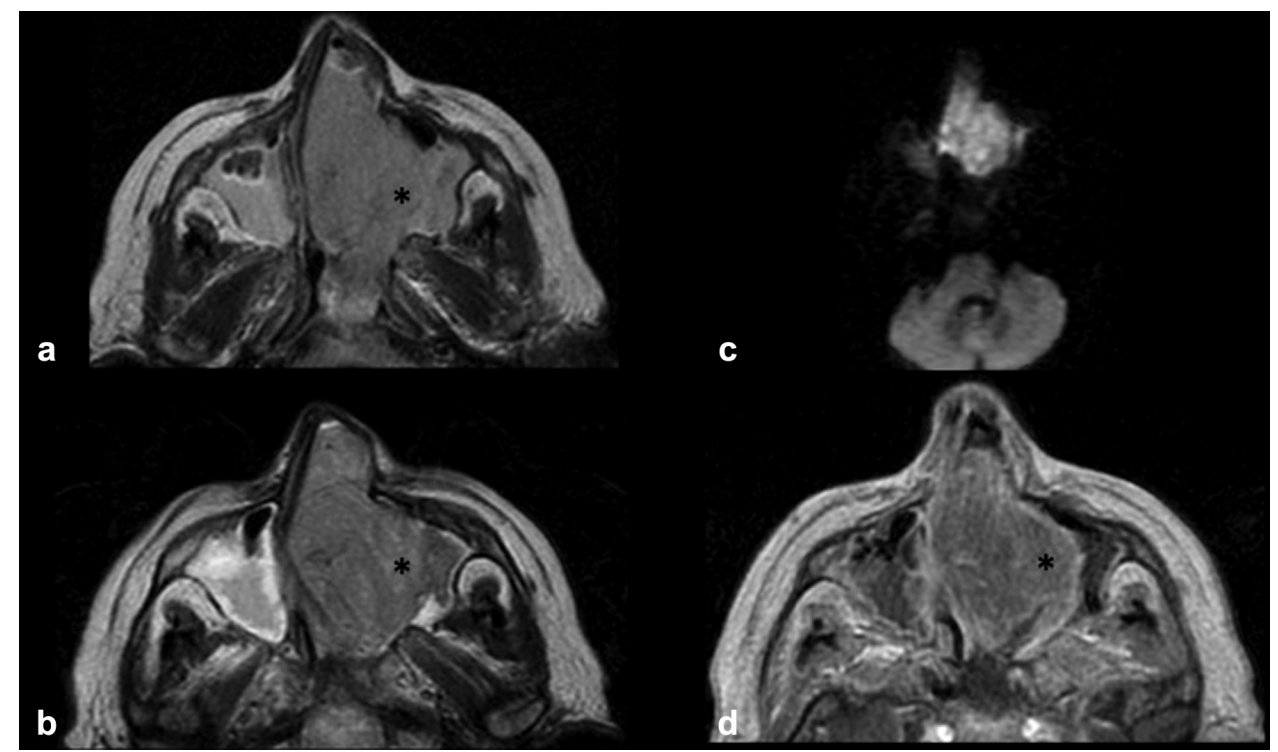

Fig. 9 RM craneoencefálica en plano axial. (a) Secuencia FLAIR. (b) Secuencia potenciada en T2. (c) Secuencia de difusión y (d) secuencia potenciada en T1 con contraste paramagnético (Gadolinio). Lesión ocupante de espacio localizada en fosa nasal que da lugar a destrucción ósea e invasión de seno maxilar izquierdo (asterisco negro). La masa presenta una moderada restricción de la difusión hídrica y realza tras la administración de contraste paramagnético.

anterior; T2, el tumor se extiende a órbita o protruye en la fosa craneal anterior; T3, el tumor afecta al cerebro con márgenes resecables; y T4 cuando el tumor es irresecable.

Dulguerov y Calcaterra, ${ }^{19}$ en 1992, proponen una clasificación basada en el sistema TNM (-Tabla 4) con una descripción más detallada de la extensión local de la enfermedad, y teniendo en cuenta las metástasis a distancia y la diseminación a ganglios linfáticos cervicales. T1, el tumor afecta a cavidad nasal y/o senos paranasales (excluyendo esfenoides), respetando las celdillas etmoidales más craneales; T2, el tumor afecta la cavidad nasal y/o senos paranasales, incluyendo esfenoides con extensión o erosión de la placa cribiforme; T3, el tumor se extiende a órbita o protruye dentro de la fosa craneal anterior sin invasión dural; T4, el tumor afecta al cerebro. N0, si no hay afectación ganglionar cervical; N1, cualquier afectación ganglionar cervical; M0, si no hay metástasis; M1 si existe evidencia de metástasis a distancia.

\section{Tratamiento}

Las modalidades de tratamiento utilizadas y los resultados esperados dependen de la extensión del tumor y su grado histológico. Excepto en el caso de enfermedad muy temprana y limitada, el tratamiento multimodal ofrece la mejor 


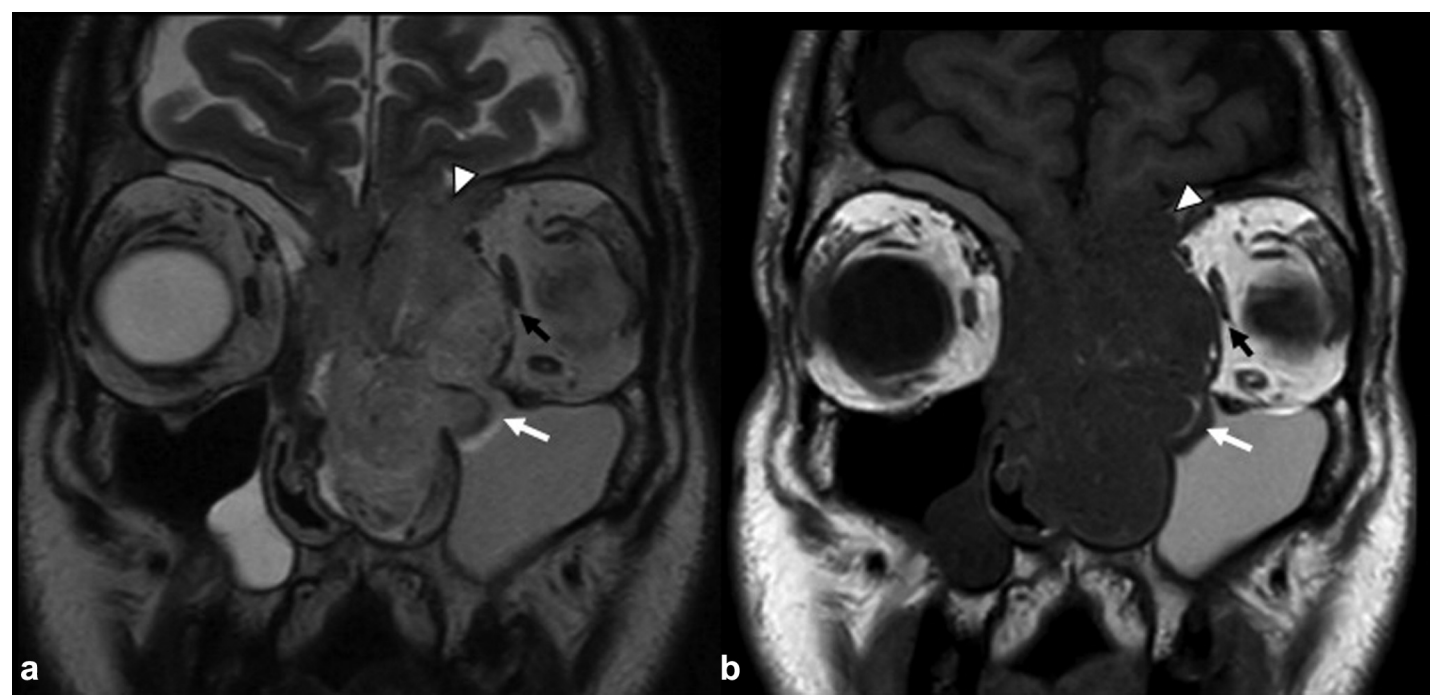

Fig. 10 RM craneoencefálica en plano coronal. (a) Secuencia potenciada en T2 y (b) Secuencia potenciada en T1. Lesión ocupante de espacio de intensidad discretamente heterogénea de predominio hiperintenso respecto a la sustancia gris en secuencia potenciada en T2 y señal levemente hipointensa en secuencia potenciada en T1, que ocupa la fosa nasal izquierda y presenta destrucción ósea con destrucción de la lámina papirácea izquierda, extensión intraorbitaria izquierda extraconal con compresión del músculo recto interno izquierdo sin aparente infiltración del mismo (flecha negra), extensión infundibular a pared medial de seno maxilar izquierdo (flecha blanca), destrucción del suelo del seno frontal izquierdo con extensión al mismo, destrucción de la lámina cribiforme izquierda con extensión intracraneal extraaxial en fosa anterior frontobasal izquierda, que parece contenida por la duramadre, apreciando dudosa disrupción dural que podría traducir una mínima ocupación del espacio subdural (punta de flecha blanca).

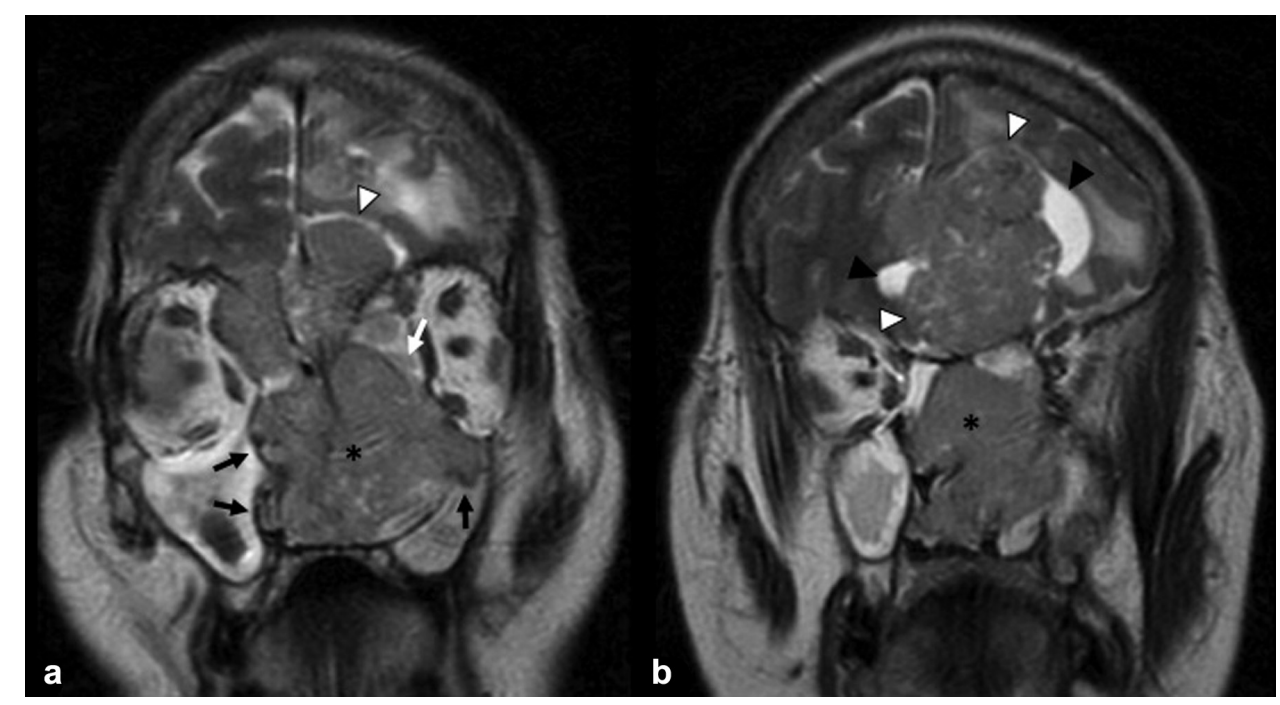

Fig. 11 Estesioneuroblastoma tipo C según la clasificación de Kadish. (a) y (b) RM craneoencefálica secuencia potenciada en T2 en plano coronal. Voluminosa lesión ocupante de espacio que presenta una intensidad de señal heterogénea y se localiza a nivel de cavidad nasal (asterisco negro), con destrucción ósea, que invade órbitas (flecha blanca), así como senos paranasales (flecha negra), nasofaringe y fosa cerebral anterior (punta de flecha blanca), donde se visualiza componente quístico periférico (punta de flecha negra).

oportunidad de curación. ${ }^{5}$ La cirugía seguida de radioterapia es considerada el tratamiento estándar por la mayoría de los centros expertos. 5,39

El enfoque quirúrgico tradicional para el NBO es la resección craneofacial anterior, incluida la craneotomía bi-frontal combinada con la rinotomía transfacial lateral. ${ }^{63}$ Esa intervención es realizada, si es necesario, por un equipo doble de otorrinolaringología y neurocirugía. En las últimas dos décadas, los enfoques endoscópicos han ganado popularidad, dando lugar a resultados oncológicos comparables, que limitan la morbilidad quirúrgica y la duración de la estancia hospitalaria. ${ }^{64}$ Inicialmente, estos se recomendaban solo en etapas precoces con mínima invasión de la base del cráneo. Sin embargo, con los avances en las técnicas endoscópicas y los métodos de reconstrucción, se utilizan cada vez más para estadios avanzados con invasión extensa, permitiendo una resección completa. ${ }^{65}$

Las contraindicaciones para los enfoques endoscópicos puros incluyen la participación de la tabla anterior del seno frontal, la piel y el tejido subcutáneo, el saco nasolagrimal, la arteria carótida y la extensa invasión intraorbital y parenquimatosa cerebral. Además, la extensión lateral por encima de la órbita y la invasión palatina se consideran también contraindicaciones para realizar abordajes endoscópicos puros y los abordajes 


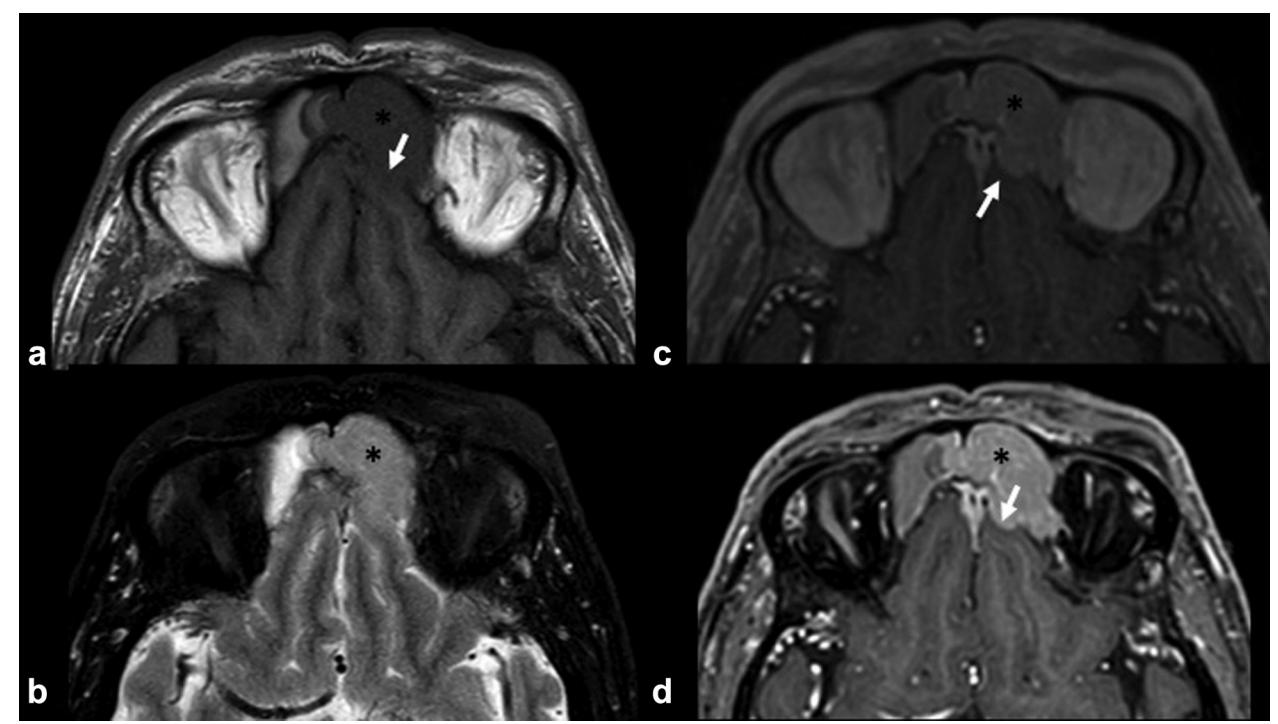

Fig. 12 RM craneoencefálica en plano axial. (a) Secuencia potenciada en T1. Lesión levemente hipointensa respecto a la sustancia gris que ocupa el seno frontal izquierdo (asterisco negro) y que destruye la pared posterior del mismo extendiéndose a fosa craneal anterior (flecha blanca). (b) Secuencia potenciada en $\mathrm{T} 2$ con supresión grasa. La lesión se muestra hiperintensa respecto a la sustancia gris en esta secuencia. (c) Secuencia potenciada en T1 con contraste paramagnético (Gadolinio) y (d) secuencia potenciada en T1 con supresión de la grasa y contraste paramagnético (Gadolinio). En esas secuencias, la lesión muestra un realce homogéneo y pone de manifiesto una infiltración subdural sin extensión encefálica.

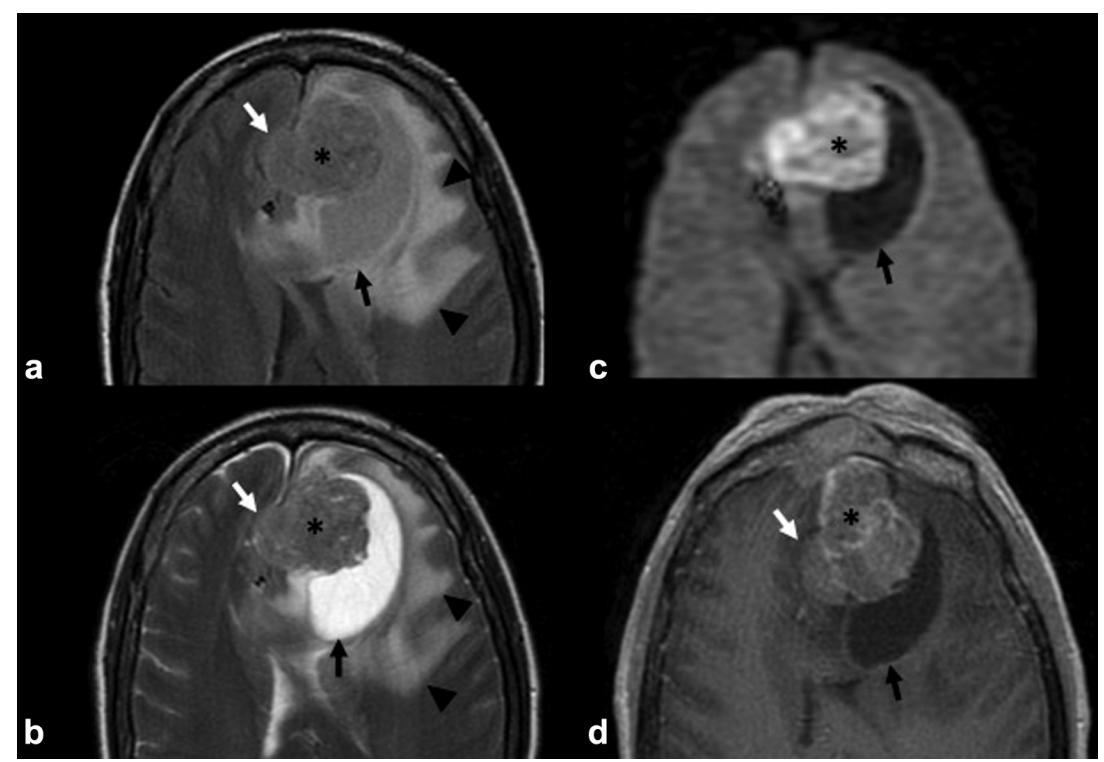

Fig. 13 RM craneoencefálica en plano axial. (a) Secuencia FLAIR. (b) Secuencia potenciada en T2. (c) Secuencia de difusión y (d) secuencia potenciada en T1 con contraste paramagnético (Gadolinio). Afectación de la fosa cerebral anterior por masa procedente de fosa nasal (asterisco negro), que a nivel de encefálico ocasiona importante efecto de masa, con presencia de cavidad quística periférica (flecha negra) e importante edema perilesional de morfología digitiforme (punta de flecha negra), que ocasiona herniación subfalcial (flecha blanca). La citada masa tiene una intensidad de señal heterogénea, hiperintensa respecto a la sustancia gris en secuencias potenciadas en T2 y presenta una moderada restricción de la difusión hídrica y un realce leve tras la administración de contraste paramagnético.

craneofaciales tradicionales están indicados en tales casos. ${ }^{63,66}$ Independientemente del enfoque, la resección total con márgenes negativos debe lograrse en todos los casos. ${ }^{63}$

Se ha demostrado que la radioterapia postoperatoria mejora el control local de la enfermedad. Sin embargo, no se ha demostrado ningún beneficio en términos de supervivencia global a largo plazo de la radioterapia adyuvante. ${ }^{13,62,67}$ Las técnicas de radioterapia conformada como la radioterapia de intensidad modulada y la terapia con haz de protones han mostrado mejores resultados, mejorando el control local y minimizando la toxicidad y las complicaciones en las estructuras críticas cercanas. ${ }^{5,68}$

En general, la quimioterapia puede considerarse en pacientes con estadio avanzado, alto grado de Hyams, enfermedad regional extensa, metástasis a distancia, márgenes positivos, tumores no resecables y tumores recurrentes. ${ }^{69}$ No existe un régimen estándar de quimioterapia para tratar el NBO. Algunos autores informaron el uso de ciclofosfamida, vincristina y 


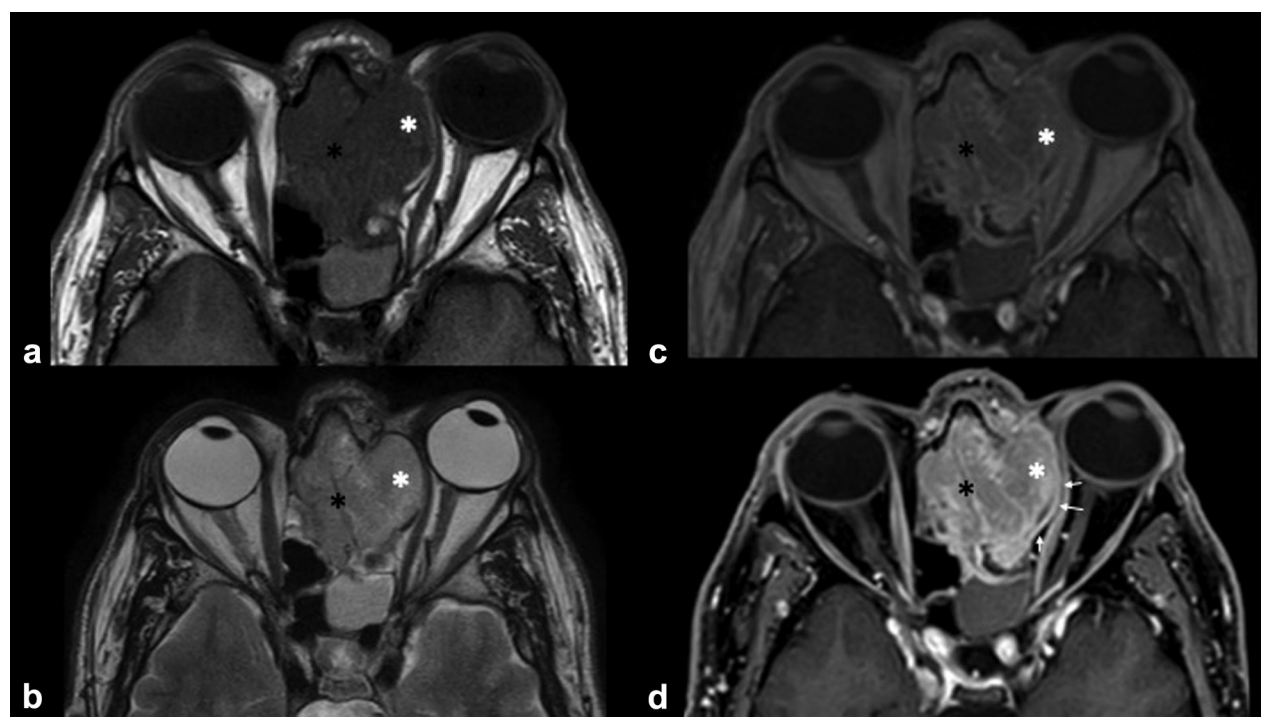

Fig. 14 RM craneoencefálica en plano axial- (a) Secuencia potenciada en T1. (b) Secuencia potenciada en T2. (c) Secuencia potenciada en T1 con contraste paramagnético (Gadolinio) y (d) secuencia potenciada en T1 con supresión de la grasa y contraste paramagnético (Gadolinio). Lesión ocupante de espacio, hipointensa respecto a la sustancia gris en secuencias potenciadas en T1 y moderadamente hiperintensa en secuencias potenciadas en $T 2$ con captación heterogénea de contraste, que ocupa fosa nasal izquierda (asterisco negro) y celdillas etmoidales y destruye la lámina orbitaria izquierda, con extensión intraorbitaria extraconal (asterisco blanco) y compresión del músculo recto interno izquierdo sin aparente infiltración del mismo. Eso se valora mejor en las secuencias con saturación grasa (d), donde se objetiva una línea de separación hipointensa entre la lesión y músculo (interfaz tumor-grasa) (flechas blancas), que sugiere que la lesión está contenida en la fascia periorbital.

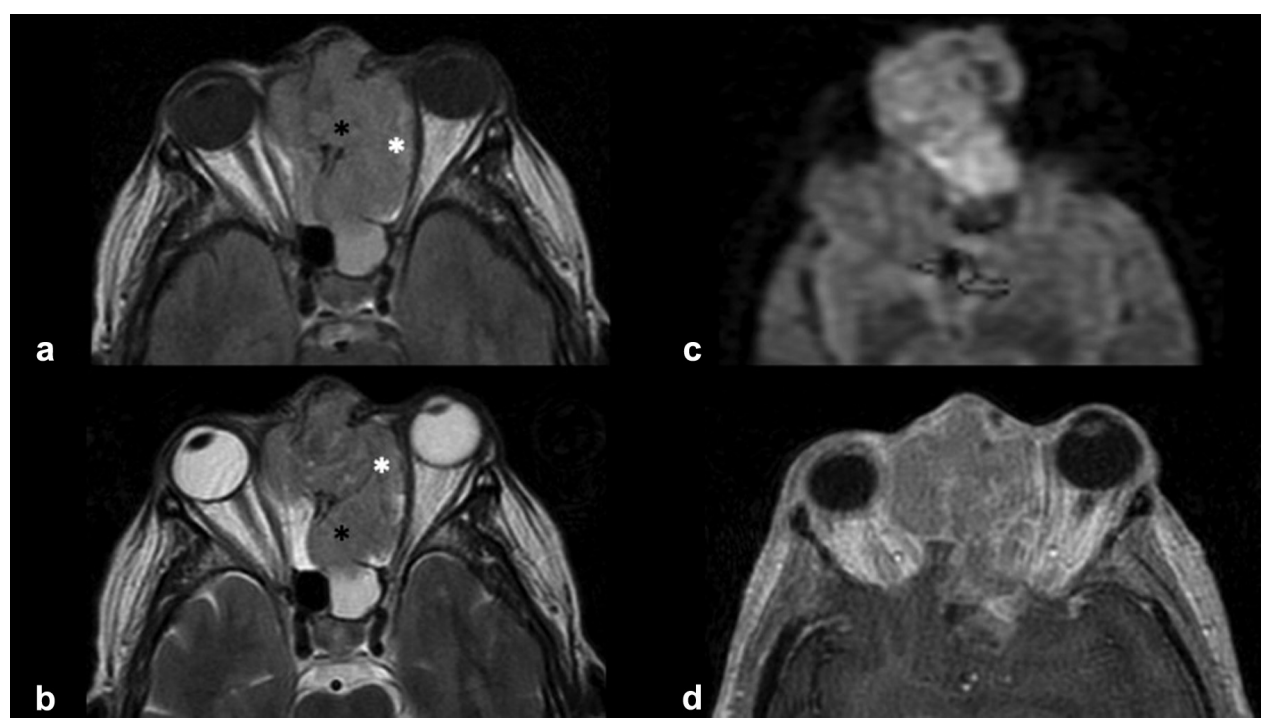

Fig. 15 RM craneoencefálica en plano axial. (a) Secuencia FLAIR. (b) Secuencia potenciada en T2. (c) Secuencia de difusión y (d) secuencia potenciada en T1 con contraste paramagnético (Gadolinio). Lesión ocupante de espacio localizada en fosa nasal y celdillas etmoidales que presenta destrucción ósea (asterisco negro) e invasión orbitaria extraconal (asterisco blanco). La masa es discretamente hiperintensa respecto a la sustancia gris en secuencias potenciadas en $\mathrm{T} 2$ y presenta una moderada restricción de la difusión hídrica y un discreto realce tras la administración de contraste paramagnético.

doxorrubicina, mientras que otros consideraron el uso de regímenes basados en cisplatino. ${ }^{70}$

El cisplatino combinado con etopósido parece ser el régimen más popular utilizado para NBO. ${ }^{71,72}$ La quimioterapia adyuvante puede agregar una mejora en el control locorregional y prolonga el tiempo medio hasta la recaída. Sin embargo, no mejora la supervivencia general. ${ }^{68}$

Las tasas generales de supervivencia son inconsistentes entre diferentes estudios. Konuthula y colaboradores ${ }^{62}$ analizaron la superviviencia de 1,107 pacientes de la
National Cancer Database (NCDB), y encontraron que la supervivencia de las diferentes modalidades de tratamiento del ENB, no estaba clara debido al bajo número de pacientes. Aunque la combinación de cirugía y radioterapia se ha utilizado con mayor frecuencia y se ha demostrado que tiene una supervivencia de alrededor del $65 \%$, muchos pacientes todavía están siendo tratados con cirugía o RT solo, ya que no se ha demostrado una diferencia estadísticamente significativa para las diferentes modalidades de tratamiento. Cuando la cirugía sola y la 


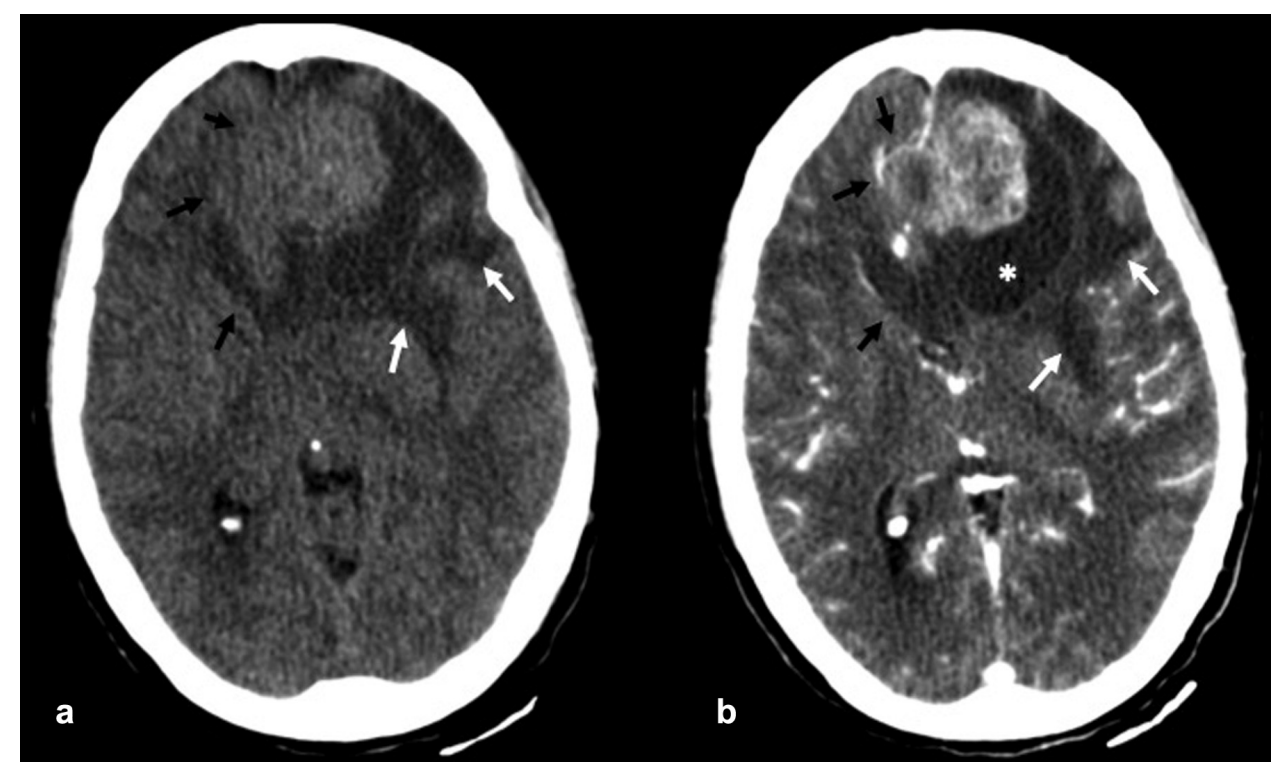

Fig. 16 TC craneoencefálica plano axial (a) sin contraste intravenoso y (b) con contraste intravenoso yodado. Extensión intracraneal parenquimatosa con afectación frontal izquierda extensa ocupando línea media. Se visualiza un efecto de masa parenquimatoso cerebral con edema circundante (flechas blancas) y herniación subfalcial asociada con desviación de línea media a la derecha (flechas negras). Tras la administración de contraste intravenoso, se aprecia un componente quístico en región frontal izquierda (asterisco blanco).

Tabla 2 Clasificación de Kadish modificada por Morita y colaboradores

\begin{tabular}{|l|l|}
\hline ESTADIO & DESCRIPCIÓN \\
\hline A & Tumor limitado a la cavidad nasal \\
\hline B & Tumor se extiende a senos paranasales \\
\hline C & $\begin{array}{l}\text { Tumor se extiende más allá de senos } \\
\text { paranasales, incluyendo placa cribiforme, } \\
\text { base del cráneo, cavidad intracraneal y orbita }\end{array}$ \\
\hline D & $\begin{array}{l}\text { Tumor con diseminación a los ganglios } \\
\text { linfáticos de la región cervical y/o } \\
\text { metástasis a distancia }\end{array}$ \\
\hline
\end{tabular}

Tabla 3 Clasificación de Biller

\begin{tabular}{|l|l|}
\hline GRADO & DESCRIPCIÓN \\
\hline T1 & $\begin{array}{l}\text { Tumor afecta a la cavidad nasal y senos } \\
\text { paranasales, excluyendo el esfenoides, } \\
\text { con o sin erosión del hueso de la fosa } \\
\text { craneal anterior }\end{array}$ \\
\hline T2 & $\begin{array}{l}\text { Tumor se extiende a órbita o protruye en la } \\
\text { fosa craneal anterior }\end{array}$ \\
\hline T3 & $\begin{array}{l}\text { Tumor afecta al cerebro con márgenes } \\
\text { resecables }\end{array}$ \\
\hline T4 & Tumor irresecable \\
\hline
\end{tabular}

cirugía con radioterapia adyuvante se compararon entre las diferentes etapas de Kadish modificada, tampoco se obtuvieron diferencias en la supervivencia entre los dos grupos en las etapas A, B y D. Sin embargo, para los pacientes en estadio Kadish C, la cirugía con radioterapia adyuvante tuvo mayor supervivencia que la cirugía sola. ${ }^{62}$
Tabla 4 Clasificación basada en el sistema TNM de Dulguerov y Calcaterra

\begin{tabular}{|l|l|}
\hline CLASIFICACIÓN & DEFINICIÓN \\
\hline TUMOR & $\begin{array}{l}\text { Tumor afecta a cavidad nasal y/o senos } \\
\text { paranasales (excluyendo esfenoides), } \\
\text { respetando las celdillas etmoidales } \\
\text { más craneales }\end{array}$ \\
\hline T1 & $\begin{array}{l}\text { Tumor afecta la cavidad nasal y/o senos } \\
\text { paranasales, incluyendo esfenoides con } \\
\text { extensión o erosión de la placa cribiforme }\end{array}$ \\
\hline T2 & $\begin{array}{l}\text { Tumor se extiende a orbita o protruye } \\
\text { dentro de la fosa craneal anterior sin } \\
\text { invasión dural }\end{array}$ \\
\hline T3 & Tumor afecta al cerebro. \\
\hline GANGLIOS LINFÁTICOS \\
\hline N0 & No afectación ganglionar cervical \\
\hline N1 & Cualquier afectación ganglionar cervical \\
\hline METÁSTASIS & \multicolumn{2}{|l}{} \\
\hline M0 & No metástasis \\
\hline M1 & Metástasis a distancia \\
\hline
\end{tabular}

\section{Conclusión}

El neuroblastoma olfatorio es una neoplasia maligna poco frecuente. Su diagnóstico se basa en las pruebas de imagen, en la anatomía patológica y las pruebas inmunohistoquímicas. Por lo tanto, los radiólogos juegan un papel primordial en su diagnóstico. Para ello, deben conocer sus hallazgos de imagen característicos en las diferentes pruebas de imagen (TC y RM), y las diferentes estadificaciones que permiten realizar el diagnóstico de 
extensión. La terapia óptima depende de la extensión del tumor y su grado histológico, siendo de elección el tratamiento multimodal con la combinación de cirugía y radiación con o sin quimioterapia, aunque depende de la experiencia de cada centro.

\section{Responsabilidades Éticas}

Protección de personas y animales. Los autores declaran que para esta investigación no se han realizado experimentos en seres humanos ni en animales.

Confidencialidad de los datos. Los autores declaran que han seguido los protocolos de su centro de trabajo sobre la publicación de datos de pacientes.

Derecho a la privacidad y consentimiento informado. Los autores declaran que en este artículo no aparecen datos de pacientes.

Fuentes de financiación No han existido fuentes de financiación para la realización de este trabajo.

\section{Conflicto de Intereses}

Los autores declaran no tener ningún conflicto de intereses.

\section{Agradecimientos}

Los autores agradecen el apoyo y la colaboración de todos los compañeros que han participado en este trabajo.

\section{Bibliografía}

1 Bell D, Franchi A, Gillison M, Thompson LDR, Wenig BM. Olfactory neuroblastoma. En: El-Naggar AK, Chan JKC, Grandis JR, Takata T, Slootweg PJ, eds. WHO classification of head and neck tumors. 4th ed. Lyon: IAC Press; 2017:57-59

2 Berger L, Luc R, Richard D. L'esthesioneuroepitheliome Olfactif. Bull Assoc Fr Etud Cancer. 1924;13:410-421

3 Su SY, Bell D, Hanna EY. Esthesioneuroblastoma, neuroendocrine carcinoma, and sinonasal undifferentiated carcinoma: differentiation in diagnosis and treatment. Int Arch Otorhinolaryngol. 2014;18(02, Suppl 2):S149-S156

4 Bell D, Saade R, Roberts D, Ow TJ, Kupferman M, DeMonte F, et al. Prognostic utility of Hyams histological grading and KadishMorita staging systems for esthesioneuroblastoma outcomes. Head Neck Pathol. 2015;9(01):51-59

5 Ow TJ, Bell D, Kupferman ME, Demonte F, Hanna EY. Esthesioneuroblastoma. Neurosurg Clin N Am. 2013;24(01):51-65

6 Faragalla H, Weinreb I. Olfactory neuroblastoma: a review and update. Adv Anat Pathol. 2009;16(05):322-331

7 Holbrook EH, Wu E, Curry WT, Lin DT, Schwob JE. Immunohistochemical characterization of human olfactory tissue. Laryngoscope. 2011;121(08):1687-1701

8 Trojanowski JQ Lee V, Pillsbury N, Lee S. Neuronal origin of human esthesioneuroblastoma demonstrated with anti-neurofilament monoclonal antibodies. N Engl J Med. 1982;307(03):159-161

9 Carney ME, O'Reilly RC, Sholevar B, Buiakova OI, Lowry LD, Keane WM, et al. Expression of the human Achaete-scute 1 gene in olfactory neuroblastoma (esthesioneuroblastoma). Neurooncol. 1995;26(01):35-43

10 Mills SE. Neuroectodermal neoplasms of the head and neck with emphasis on neuroendocrine carcinomas. Mod Pathol. 2002;15 (03):264-278

11 Barnes L, Eveson JW, Reichart P, Sidransky D. Pathology and genetics of head and neck tumours. World Health Organization (WHO) Classification of Tumours. Lyon: IARC Press; 2005:168-175
12 Jethanamest D, Morris LG, Sikora AG, Kutler DI. Esthesioneuroblastoma: a population-based analysis of survival and prognostic factors. Arch Otolaryngol Head Neck Surg. 2007; 133(03):276-280

13 Platek ME, Merzianu M, Mashtare TL, Popat SR, Rigual NR, Warren $\mathrm{GW}$, et al. Improved survival following surgery and radiation therapy for olfactory neuroblastoma: analysis of the SEER database. Radiat Oncol. 2011;6:41

14 Chao KS, Kaplan C, Simpson JR, Haughey B, Spector GJ, Sessions DG, et al. Esthesioneuroblastoma: the impact of treatment modality. Head Neck. 2001;23(09):749-757

15 Spaulding CA, Kranyak MS, Constable WC, Stewart FM. Esthesioneuroblastoma: a comparison of two treatment eras. Int J Radiat Oncol Biol Phys. 1988;15(03):581-590

16 Dias FL, Sa GM, Lima RA, Kligerman J, Leoncio MP, Freitas EQ, et al. Patterns of failure and outcome in esthesioneuroblastoma. Arch Otolaryngol Head Neck Surg. 2003;129(11):1186-1192

17 Levine PA, McLean WC, Cantrell RW. Esthesioneuroblastoma: the University of Virginia experience 1960-1985. Laryngoscope. 1986;96(07):742-746

18 Kadish S, Goodman M, Wang CC. Olfactory neuroblastoma. A clinical analysis of 17 cases. Cancer. 1976;37(03):1571-1576

19 Dulguerov P, Calcaterra T. Esthesioneuroblastoma: the UCLA experience 1970-1990. Laryngoscope. 1992;102(08):843-849

20 Rinaldo A, Ferlito A, Shaha AR, Wei WI, Lund VJ. Esthesioneuroblastoma and cervical lymph node metastases: clinical and therapeutic implications. Acta Otolaryngol. 2002;122 (02):215-221

21 Monroe AT, Hinerman RW, Amdur RJ, Morris CG, Mendenhall WM. Radiation therapy for esthesioneuroblastoma: rationale for elective neck irradiation. Head Neck. 2003;25(07):529-534

22 Davis RE, Weissler MC. Esthesioneuroblastoma and neck metastasis. Head Neck. 1992;14(06):477-482

23 Winn HR. Youmans neurological surgery: brain, spine, and peripheral nerve trauma in adults and children. Elsevier Health Sciences; 2014

24 Larbcharoensub N, Kanoksil W, Cheewaruangroj W, Wiratkapun C, Sitathanee C, Sirachainan E. Esthesioneuroblastoma metastasis to the breast: A case report and review of the literature. Oncol Lett. 2014;8(04):1505-1508

25 Schuster JJ, Phillips CD, Levine PA. MR of esthesioneuroblastoma (olfactory neuroblastoma) and appearance after craniofacial resection. AJNR Am J Neuroradiol. 1994;15(06):1169-1177

26 Shah K, Perez-Ordóñez B. Neuroendocrine neoplasms of the sinonasal tract: neuroendocrine carcinomas and olfactory neuroblastoma. Head Neck Pathol. 2016;10(01):85-94

27 Bell D, Hanna E, Weber R, DeMonte F, Triantafyllou A, Lewis Jr, et al. Neuroendocrine neoplasms of the sinonasal region. Head Neck. 2016;38(Suppl 1):E2259-E2266

28 Wooff JC, Weinreb I, Perez-Ordonez B, Magee JF, Bullock MJ. Calretinin staining facilitates differentiation of olfactory neuroblastoma from other small round blue cell tumors in the sinonasal tract. Am J Surg Pathol. 2011;35(12):1786-1793

29 Argani P, Perez-Ordoñez B, Xiao H, Caruana SM, Huvos AG, Ladanyi M. Olfactory neuroblastoma is not related to the Ewing family of tumors: absence of EWS/FLI1 gene fusion and MIC2 expression. Am J Surg Pathol. 1998;22(04):391-398

30 Hyams V, Batsakis J, Michaels L. Tumors of the upper respiratory tract and ear. Armed forces institute of pathology fascicles, 2nd series. Washington: American Registry of Pathology Press; 1988

31 Wenig BM. Undifferentiated malignant neoplasms of the sinonasal tract. Arch Pathol Lab Med. 2009;133(05):699-712

32 Purdy Stout A, Lattes R. Atlas of tumor pathology. Washington: Armed Forced Institute of Pathology; 1967

33 Bradley PJ, Jones NS, Robertson I. Diagnosis and management of esthesioneuroblastoma. Curr Opin Otolaryngol Head Neck Surg. 2003;11(02):112-118 
34 Kaur G, Kane AJ, Sughrue ME, Madden M, Oh MC, Sun MZ, et al. The prognostic implications of Hyam's subtype for patients with Kadish stage C esthesioneuroblastoma. J Clin Neurosci. 2013;20 (02):281-286

35 Dublin AB. Imaging characteristics of olfactory neuroblastoma. J Neurol Surg B Skull Base. 2007;17(S1):A091

36 Lund VJ, Milroy C. Olfactory neuroblastoma: clinical and pathological aspects. Rhinology. 1993;31(01):1-6

37 Bailey BJ, Barton S. Olfactory neuroblastoma. Management and prognosis. Arch Otolaryngol. 1975;101(01):1-5

38 Bak M, Wein RO. Esthesioneuroblastoma: a contemporary review of diagnosis and management. Hematol Oncol Clin North Am. 2012;26(06):1185-1207

39 Ow TJ, Hanna EY, Roberts DB, et al. Optimization of long-term outcomes for patients with esthesioneuroblastoma. Head Neck. 2014;36(04):524-530

40 Holland H, Koschny R, Krupp W, et al. Comprehensive cytogenetic characterization of an esthesioneuroblastoma. Cancer Genet Cytogenet. 2007;173(02):89-96

41 Bockmühl U, You X, Pacyna-Gengelbach M, Arps H, Draf W, Petersen I. CGH pattern of esthesioneuroblastoma and their metastases. Brain Pathol. 2004;14(02):158-163

42 Guled M, Myllykangas S, Frierson HF Jr, Mills SE, Knuutila S, Stelow EB. Array comparative genomic hybridization analysis of olfactory neuroblastoma. Mod Pathol. 2008;21(06):770-778

43 Modesto A, Blanchard P, Tao YG, Rives M, Janot F, Serrano E, et al. Multimodal treatment and long-term outcome of patients with esthesioneuroblastoma. Oral Oncol. 2013;49(08):830-834

44 Suriano M, De Vincentiis M, Colli A, Benfari G, Mascelli A, Gallo A. Endoscopic treatment of esthesioneuroblastoma: a minimally invasive approach combined with radiation therapy. Otolaryngol Head Neck Surg. 2007;136(01):104-107

45 Ward PD, Heth JA, Thompson BG, Marentette LJ. Esthesioneuroblastoma: results and outcomes of a single institution's experience. Skull Base. 2009;19(02):133-140

46 Josephs L, Jones L, Marenette L, McKeever P. Cushing's syndrome: an unusual presentation of olfactory neuroblastoma. Skull Base. 2008;18(01):73-76

47 Koo BK, An JH, Jeon KH, Choi SH, Cho YM, Jang HC, et al. Two cases of ectopic adrenocorticotropic hormone syndrome with olfactory neuroblastoma and literature review. Endocr J. 2008;55(03): 469-475

48 Plasencia YL, Cortés MB, Arencibia DM, Dámaso TM, Contreras IL, Pino AO, et al. Esthesioneuroblastoma recurrence presenting as a syndrome of inappropriate antidiuretic hormone secretion. Head Neck. 2006;28(12):1142-1146

49 Dulguerov P, Allal AS, Calcaterra TC. Esthesioneuroblastoma: a meta-analysis and review. Lancet Oncol. 2001;2(11):683-690

50 Manelfe C, Bonafé A, Fabre P, Pessey JJ. Computed tomography in olfactory neuroblastoma: one case of esthesioneuroepithelioma and four cases of esthesioneuroblastoma. J Comput Assist Tomogr. 1978;2(04):412-420

51 Ahmed M, Knott PD. Hyperostotic esthesioneuroblastoma: rare variant and fibrous dysplasia mimicker. Korean J Radiol. 2014;15 (01):156-160

52 Howell MC, Branstetter BF IV, Snyderman CH. Patterns of regional spread for esthesioneuroblastoma. AJNR Am J Neuroradiol. 2011; 32(05):929-933

53 Ahmad A, Branstetter BF IV. CT versus MR: still a tough decision. Otolaryngol Clin North Am. 2008;41(01):1-22, v

54 Ling FTK, Kountakis SE. Advances in imaging of the paranasal sinuses. Curr Allergy Asthma Rep. 2006;6(06):502-507

55 Branstetter BF IV, Weissman JL. Role of MR and CT in the paranasal sinuses. Otolaryngol Clin North Am. 2005;38(06):1279-1299, x

56 Som PM, Lidov M, Brandwein M, Catalano P, Biller HF. Sinonasal esthesioneuroblastoma with intracranial extension: marginal tumor cysts as a diagnostic MR finding. AJNR Am J Neuroradiol. 1994;15(07):1259-1262
57 Sievers KW, Greess H, Baum U, Dobritz M, Lenz M. Paranasal sinuses and nasopharynx CT and MRI. Eur J Radiol. 2000;33(03): 185-202

58 Koka VN, Julieron M, Bourhis J, Janot F, Le Ridant AM, Marandas P, et al. Aesthesioneuroblastoma. J Laryngol Otol. 1998;112(07): 628-633

59 Slevin NJ, Irwin CJ, Banerjee SS, Gupta NK, Farrington WT. Olfactory neural tumours-the role of external beam radiotherapy. J Laryngol Otol. 1996;110(11):1012-1016

60 Morita A, Ebersold MJ, Olsen KD, Foote RL, Lewis JE, Quast LM. Esthesioneuroblastoma: prognosis and management. Neurosurgery. 1993;32(05):706-714, discussion 714-715

61 Biller HF, Lawson W, Sachdev VP, Som P. Esthesioneuroblastoma: surgical treatment without radiation. Laryngoscope. 1990;100 (11):1199-1201

62 Konuthula N, Iloreta AM, Miles B, Rhome R, Ozbek U, Genden EM, et al. Prognostic significance of Kadish staging in esthesioneuroblastoma: An analysis of the National Cancer Database. Head Neck. 2017;39(10):1962-1968

63 Gallia GL, Reh DD, Salmasi V, Blitz AM, Koch W, Ishii M. Endonasal endoscopic resection of esthesioneuroblastoma: the Johns Hopkins Hospital experience and review of the literature. Neurosurg Rev. 2011;34(04):465-475

64 Hanna E, DeMonte F, Ibrahim S, Roberts D, Levine N, Kupferman M. Endoscopic resection of sinonasal cancers with and without craniotomy: oncologic results. Arch Otolaryngol Head Neck Surg. 2009;135(12):1219-1224

65 Diaz EM Jr, Johnigan RH 3rd, Pero C, El-Naggar AK, Roberts DB, Barker JL, et al. Olfactory neuroblastoma: the 22-year experience at one comprehensive cancer center. Head Neck. 2005;27(02): 138-149

66 Su SY, Kupferman ME, DeMonte F, Levine NB, Raza SM, Hanna EY. Endoscopic resection of sinonasal cancers. Curr Oncol Rep. 2014; 16(02):369

67 Kane AJ, Sughrue ME, Rutkowski MJ, Aranda D, Mills SA, Buencamino R, et al. Posttreatment prognosis of patients with esthesioneuroblastoma. J Neurosurg. 2010;113(02):340-351

68 Schwartz JS, Palmer JN, Adappa ND. Contemporary management of esthesioneuroblastoma. Curr Opin Otolaryngol Head Neck Surg. 2016;24(01):63-69

69 Folbe A, Herzallah I, Duvvuri U, Bublik M, Sargi Z, Snyderman CH, et al. Endoscopic endonasal resection of esthesioneuroblastoma: a multicenter study. Am J Rhinol Allergy. 2009;23(01): 91-94

70 Loy AH, Reibel JF, Read PW, Thomas CY, Newman SA, Jane JA, et al. Esthesioneuroblastoma: continued follow-up of a single institution's experience. Arch Otolaryngol Head Neck Surg. 2006;132(02):134-138

71 Saade RE, Hanna EY, Bell D. Prognosis and biology in esthesioneuroblastoma: the emerging role of Hyams grading system. Curr Oncol Rep. 2015;17(01):423

72 Bhattacharyya N, Thornton AF, Joseph MP, Goodman ML, Amrein PC. Successful treatment of esthesioneuroblastoma and neuroendocrine carcinoma with combined chemotherapy and proton radiation. Results in 9 cases. Arch Otolaryngol Head Neck Surg. 1997; 123(01):34-40

73 Loy AH, Reibel JF, Read PW, Thomas CY, Newman SA, Jane JA, et al. Esthesioneuroblastoma: continued follow-up of a single institution's experience. Arch Otolaryngol Head Neck Surg. 2006;132(02):134-138

74 Saade RE, Hanna EY, Bell D. Prognosis and biology in esthesioneuroblastoma: the emerging role of Hyams grading system. Curr Oncol Rep. 2015;(17):1-5

75 Bhattacharyya N, Thornton AF, Joseph MP, Goodman ML, Amrein PC. Successful treatment of esthesioneuroblastoma and neuroendocrine carcinoma with combined chemotherapy and proton radiation: results in 9 cases. Arch Otolaryngol Head Neck Surg. 1997;123(01):34-40 